Research Article

\title{
The Influence of Calcium Chloride Salt Solution on the Transport Properties of Cementitious Materials
}

\author{
Yaghoob Farnam, Taylor Washington, and Jason Weiss \\ Lyles School of Civil Engineering, Purdue University, 550 Stadium Mall Drive, West Lafayette, IN 47907, USA \\ Correspondence should be addressed to Yaghoob Farnam; yaghoob.farnam@gmail.com
}

Received 12 February 2015; Accepted 12 May 2015

Academic Editor: Ghassan Chehab

Copyright (c) 2015 Yaghoob Farnam et al. This is an open access article distributed under the Creative Commons Attribution License, which permits unrestricted use, distribution, and reproduction in any medium, provided the original work is properly cited.

\begin{abstract}
The chemical interaction between calcium chloride $\left(\mathrm{CaCl}_{2}\right)$ and cementitious binder may alter the transport properties of concrete which are important in predicting the service life of infrastructure elements. This paper presents a series of fluid and gas transport measurements made on cementitious mortars before and after exposure to various solutions with concentrations ranging from $0 \%$ to $29.8 \% \mathrm{CaCl}_{2}$ by mass. Fluid absorption, oxygen diffusivity, and oxygen permeability were measured on mortar samples prepared using Type I and Type V cements. Three primary factors influence the transport properties of mortar exposed to $\mathrm{CaCl}_{2}:(1)$ changes in the degree of saturation, (2) calcium hydroxide leaching, and (3) formation of chemical reaction products (i.e., Friedel's salt, Kuzel's salt, and calcium oxychloride). It is shown that an increase in the degree of saturation decreases oxygen permeability. At lower concentrations ( $<\sim 12 \% \mathrm{CaCl}_{2}$ at room temperature), the addition of $\mathrm{CaCl}_{2}$ can increase calcium hydroxide leaching, thereby increasing mortar porosity (this is offset by the formation of Friedel's salt and Kuzel's salt that can block the pores). At higher concentrations (> 12\%), the formation of chemical reaction products (mainly calcium oxychloride) is a dominant factor decreasing the fluid and gas transport in concrete.
\end{abstract}

\section{Introduction}

The transport properties of cementitious materials are increasingly being used to predict the service life of infrastructure element $[1,2]$. The importance of transport properties has been discussed for over six decades with pioneering work by Powers et al. [3]. Since that time, researchers have attempted to describe concrete durability $[4,5]$, concrete deterioration $[5,6]$, initiation of steel corrosion in reinforced concrete elements $[1,2]$, and concrete freeze-thaw resistance [7-12] using a variety of transport measurements.

While we frequently assume that the fluid in the concrete pores is water, this may not always be true. Salts can alter the transport properties of cementitious materials in several different ways. First, salt can change the properties of a solution including the viscosity, surface tension, and density [13-15]. These variations in viscosity, density, and surface tension can alter the rate of solution ingress into concrete [16-18]. Second, exposure to salt can increase the saturation state of concrete pores due to increasing the equilibrium relative humidity of the solution (i.e., the relative humidity of the surrounding atmosphere when a solution neither gains nor losses moisture which is related to equilibrium water activity) $[13,19]$. Third, salt can precipitate and crystallize inside concrete pores, thereby filling/blocking the pores [20, 21]. Finally, salt can react with the hydrated cementitious binder forming new chemical products which can reduce the porosity and further block the concrete pores [22-25].

Different chloride based salts can influence the transport properties of cementitious materials in different ways as the copresent cations (e.g., $\mathrm{Na}^{+}, \mathrm{Ca}^{++}$, and $\mathrm{Mg}^{++}$) may play an important role in the rate of chloride ingress. Furthermore, chemical reactions can occur between salt and the hydrated cementitious binder. While $\mathrm{NaCl}$ appears to cause a relatively small change in transport properties, $\mathrm{CaCl}_{2}$ and $\mathrm{MgCl}_{2}$ can exhibit more dramatic change in comparison to $\mathrm{NaCl}$ [24, 26, 27]. Solution containing $\mathrm{CaCl}_{2}$ and $\mathrm{MgCl}_{2}$ may result in the formation of chemical phases (e.g., Friedel's salt, Kuzel's salt, calcium oxychloride, magnesium oxychloride, brucite, or magnesium silicate hydrate) [22, 23, 25]. 


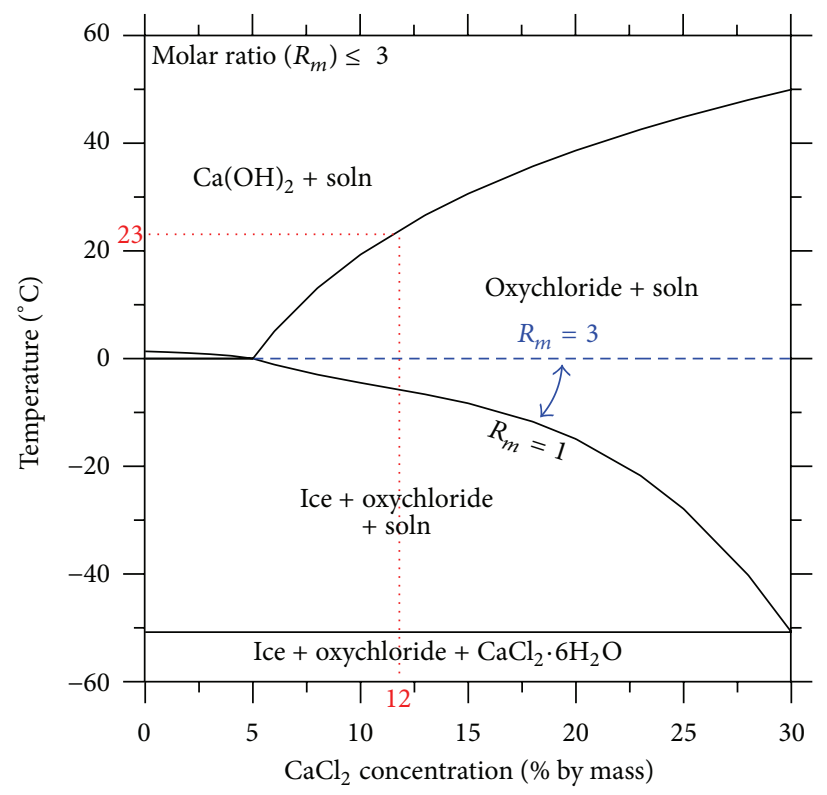

(a)

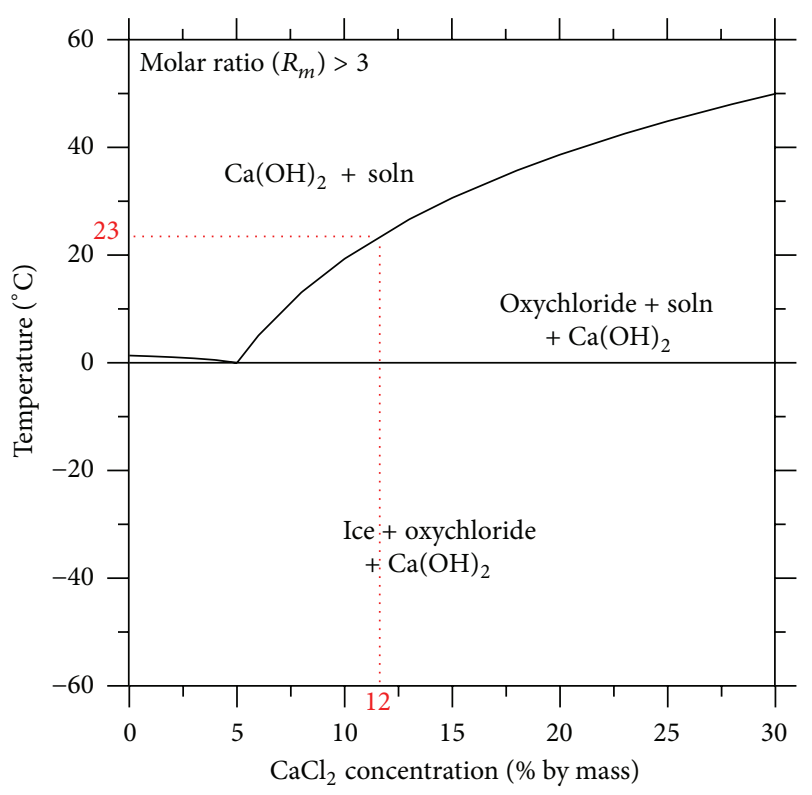

(b)

Figure 1: $\mathrm{CaCl}_{2}-\mathrm{Ca}(\mathrm{OH})_{2}-\mathrm{H}_{2} \mathrm{O}$ phase diagram for different $\mathrm{Ca}(\mathrm{OH})_{2} / \mathrm{CaCl}_{2}$ molar ratios $\left(R_{m}\right)$ developed from [22].

The formation of calcium oxychloride in addition to Friedel's salt and Kuzel's salt can block concrete pores and decrease fluid ingress into concrete samples [22, 27]. Figure 1 shows a phase diagram for a system containing calcium chloride, calcium hydroxide $(\mathrm{CH})$, and water for two molar ratios, $R_{m}$ (i.e., $R_{m}<3$ and $R_{m}>3$ ) [22]. This phase diagram can be used to interpret the formation of calcium oxychloride in a cementitious material when it is exposed to $\mathrm{CaCl}_{2}$ solution. Calcium oxychloride forms at room temperature (i.e., $23^{\circ} \mathrm{C}$ ) for $\mathrm{CaCl}_{2}$ salt concentrations at or above $\sim 12 \%$ by mass in the solution. For concentrations greater than $\sim 12 \%$, calcium oxychloride is stable (depending on the relative humidity and the temperature of the surrounding environment) [22, $26,28]$ and the amount of calcium oxychloride increases as the salt concentration increases (in the presence of sufficient solution) [29]. These expansive products can fill in a large volume of pores and reduce solution transport in concrete.

In previous studies $[22,26-28]$, it has been shown that $\mathrm{CaCl}_{2}$ solution ingress into mortar can substantially decrease when mortar samples are exposed to solutions with high concentrations of $\mathrm{CaCl}_{2}$ salt (greater than about $12 \%$ by mass). X-ray fluorescence examinations of mortar samples that were vacuum-saturated with solutions of varying $\mathrm{CaCl}_{2}$ concentrations greater than about $12 \%$ showed relatively no chloride ion ingress into the core of the samples presumably due to the blocking caused by calcium oxychloride formation [22].

This paper uses different transport tests (fluid absorption, oxygen diffusivity, and oxygen permeability) to provide an improved understanding of how $\mathrm{CaCl}_{2}$ may change the transport properties of cementitious materials. Transport properties of cementitious materials are examined on mortar samples with varying cement compositions (Type I and Type V cements) while altering the $\mathrm{CaCl}_{2}$ salt concentrations in the solution and varying the degree of saturation.

The main objective of this study is to determine whether the formation of reaction products (i.e., Friedel's salt, Kuzel's salt, and/or calcium oxychloride) is a significant factor contributing to the alteration of transport properties of cementitious materials. It is hypothesized that calcium oxychloride will not form in mortar samples exposed to $\mathrm{CaCl}_{2}$ solution with concentrations less than $\sim 12 \%$ by mass at $23^{\circ} \mathrm{C}$. It is expected that mortar samples prepared using Type $\mathrm{V}$ cement (with no tricalcium aluminate, i.e., $\mathrm{C}_{3} \mathrm{~A}$ ) will most likely produce no Friedel's salt and/or Kuzel's salt in the presence of $\mathrm{CaCl}_{2}$.

\section{Experimental Program}

Two series of experiments were performed in this study as shown in Table 1. In the first series, mortar samples were prepared and exposed to solution with varying concentrations of $\mathrm{CaCl}_{2}$ before transport testing. In the second series, mortar samples were prepared of varying levels of saturation before transport testing. This section describes the material and mixture proportioning to prepare mortar sample, conditioning of the sample, and transport testing procedure.

2.1. Materials and Mixture Proportioning. Two types of ordinary Portland cement (OPC) were used: Type I and Type V with Blaine fineness of $375 \mathrm{~m}^{2} / \mathrm{kg}$ and $316 \mathrm{~m}^{2} / \mathrm{kg}$, respectively. The chemical composition of the cements, as reported by the manufactures, is indicated in Table 2. Aggregates used to prepare mortar specimens consisted of a natural sand with a maximum size of $4.75 \mathrm{~mm}$, specific gravity of 2.61 , 
TABLE 1: Experimental program.

\begin{tabular}{llll}
\hline Experiment & Sample Type & Transport Testing & Conditioning
\end{tabular}

$\mathrm{CaCl}_{2}$ fluid absorption

(1) Being dried at $60^{\circ} \mathrm{C}$ for one week.

(2) Performing test by exposing sample to $\mathrm{CaCl}_{2}$ solution with $0 \%, 5 \%, 10 \%, 15 \%, 20 \%, 25 \%$, and $29.8 \%$ concentration by mass for two weeks.

(1) Being dried at $60^{\circ} \mathrm{C}$ for one week.

Series I: varying $\mathrm{CaCl}_{2}$ concentration
Mortar prepared using Type I and Type V cements
Oxygen diffusivity

(2) Two-week exposure to $\mathrm{CaCl}_{2}$ solution with

$0 \%, 5 \%, 10 \%, 15 \%, 20 \%, 25 \%$, and $29.8 \%$

concentration by mass.

(3) Being conditioned to reach $50 \%$ degree of saturation.

(1) Being dried at $60^{\circ} \mathrm{C}$ for one week.

(2) Two-week immersion in $\mathrm{CaCl}_{2}$ solution with

$0 \%, 5 \%, 10 \%, 15 \%, 20 \%, 25 \%$, and $29.8 \%$

Oxygen permeability concentration by mass.

(3) Being conditioned at $50 \% \pm 1 \% \mathrm{RH}$ and $23^{\circ} \mathrm{C} \pm$ $0.5^{\circ} \mathrm{C}$ for at least three months.

Series II: $\quad$ Mortar prepared using

varying degree of $\quad$ Type I and Type V Oxygen permeability

saturation cements
(1) Being dried at $60^{\circ} \mathrm{C}$ for one week.

(2) Being conditioned with DI water to reach degrees of saturation between $0 \%$ and $100 \%$.
TABLE 2: Properties of ordinary Portland cements (OPC).

\begin{tabular}{lcc}
\hline \multirow{2}{*}{ Item } & \multicolumn{2}{c}{ Percent by mass $(\%)$} \\
& Type I & Type V \\
\hline Silicon dioxide $\left(\mathrm{SiO}_{2}\right)$ & 19.43 & 21.3 \\
Aluminum oxide $\left(\mathrm{Al}_{2} \mathrm{O}_{3}\right)$ & 5.39 & 2.6 \\
Ferric oxide $\left(\mathrm{Fe}_{2} \mathrm{O}_{3}\right)$ & 3.18 & 4.2 \\
Calcium oxide $(\mathrm{CaO})$ & 63.45 & 63.2 \\
Magnesium oxide $(\mathrm{MgO})$ & 2.97 & 4.5 \\
Sulfur trioxide $\left(\mathrm{SO}_{3}\right)$ & 3.38 & 2.8 \\
Loss on ignition & 0.88 & 1.20 \\
Sodium oxide & 0.35 & $\mathrm{NA}$ \\
Potassium oxide & 0.77 & $\mathrm{NA}$ \\
Free lime & $\mathrm{NA}$ & 0.38 \\
Insoluble residue & 0.25 & 0.18 \\
Total equivalent alkali as $\mathrm{Na}_{2} \mathrm{O}$ & $\mathbf{0 . 8 6}$ & $\mathbf{0 . 2 1}$ \\
Tricalcium silicate $\left(\mathrm{C}_{3} \mathrm{~S}\right)$ & 60 & 64 \\
Dicalcium silicate $\left(\mathrm{C}_{2} \mathrm{~S}\right)$ & 10 & 13 \\
Tricalcium aluminate $\left(\mathrm{C}_{3} \mathrm{~A}\right)$ & 9 & 0 \\
Tetracalcium aluminoferrite $\left(\mathrm{C}_{4} \mathrm{AF}\right)$ & 10 & 13 \\
\hline
\end{tabular}

${ }^{*}$ Not available.

fineness modulus of 2.89 , and an absorption value of $2.2 \%$ by mass. Mortar mixtures were prepared with a sand volume fraction of $55 \%$ and a water-to-cement ratio $(w / c)$ of 0.42 by mass. Mortar was prepared in a standard mortar mixer in accordance with ASTM C305-12 [30]. The mortar was then cast in cylindrical molds $(101 \mathrm{~mm}$ in diameter and $203 \mathrm{~mm}$ in height) and large beam molds $(152 \mathrm{~mm} \times 152 \mathrm{~mm} \times 584 \mathrm{~mm})$. Samples were demolded after $24 \mathrm{~h}$ and were double-sealed in plastic bags and then cured for $42 \mathrm{~d}$ at $23^{\circ} \mathrm{C} \pm 0.5^{\circ} \mathrm{C}$ in these sealed conditions. Samples prepared using Type V cement were cured for an additional time (at $23^{\circ} \mathrm{C} \pm 0.5^{\circ} \mathrm{C}$ in the sealed condition) until the porosity reached $19.6 \%$ (i.e., the porosity of samples prepared using Type I cement after 42 days). After reaching an equal total porosity, the curing was stopped for samples prepared using Type V cement. The porosity of samples was measured according to ASTM C64213 [31] by measuring the oven-dried (at a temperature of $110 \pm$ $5^{\circ} \mathrm{C}$ for two days) mass in air, the saturated surface-dry mass in air after vacuum saturation, and the apparent mass in water after vacuum saturation.

2.2. Transport Testing. Three transport tests were used in this study: (1) fluid absorption, (2) oxygen diffusivity, and (3) oxygen permeability as indicated in Figure 2. The following sections describe the sample preparation, sample conditioning, and testing procedure for each test.

2.2.1. Fluid Absorption. After curing, cylindrical mortar samples (101 $\mathrm{mm}$ in diameter and $203 \mathrm{~mm}$ in height) were cut into smaller cylindrical samples using a wet saw $(101 \mathrm{~mm}$ in diameter and $50 \mathrm{~mm}$ in height) for the fluid absorption test. Two smaller cylindrical samples were obtained from the center of each cylindrical mortar that was cast. Then, the outer circumference of the specimen was sealed with two layers of epoxy resin as shown in Figure 2(a). Once the epoxy had hardened, the samples were then placed in an oven at $60^{\circ} \mathrm{C} \pm 0.5^{\circ} \mathrm{C}$ for one week to remove the moisture and bring the samples to mass equilibrium.

Fluid absorption testing was performed using procedure similar to ASTM C1585-11 [32], as shown in Figure 2(a). One circular face of a sample was exposed to a solution while the opposite face was covered by a loose plastic (Figure 2(a)). The mass change due to fluid absorption was then monitored over time. Solutions with $0 \%, 5 \%, 10 \%, 15 \%, 20 \%, 25 \%$, and $29.8 \% \mathrm{CaCl}_{2}$ salt concentration by mass were used. Three 


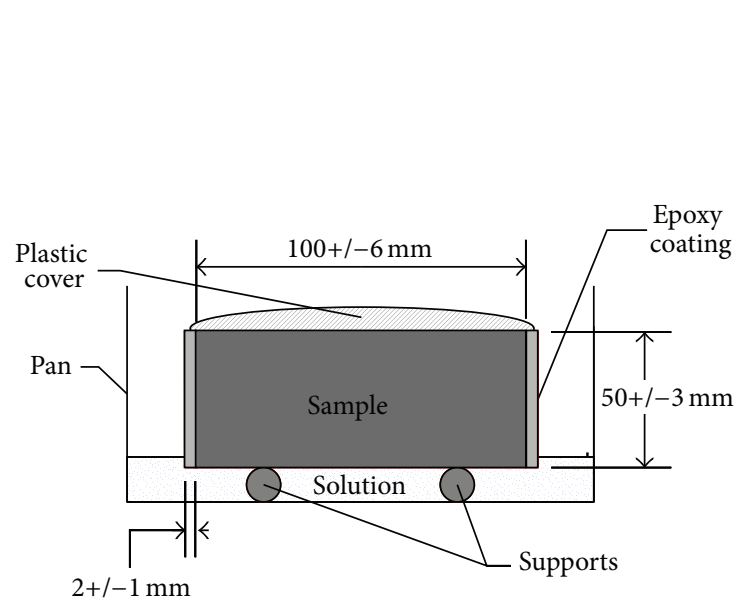

(a)

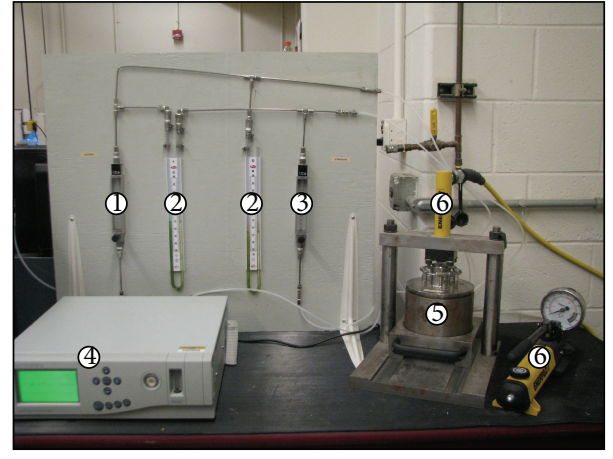

(1) Oxygen flowmeter (4) Oxygen analyzer

$\begin{array}{lll}\text { (2) Manometer } & \text { (5) Sample inside chamber }\end{array}$

(3) Nitrogen flowmeter
(6) Hydraulic jack

(b)

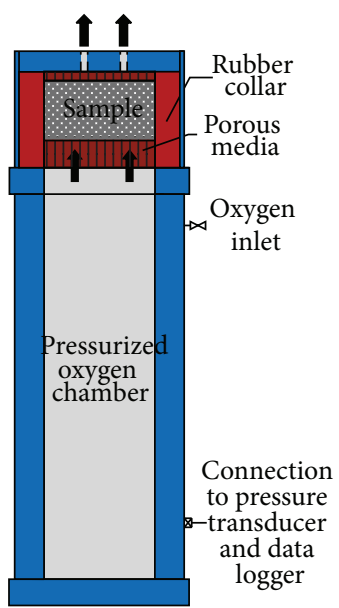

(c)

FIGURE 2: Experimental procedure: (a) fluid absorption test, (b) oxygen diffusivity test, and (c) oxygen permeability test.

samples were exposed to each solution for 2 weeks. All fluid absorption tests were performed at room temperature $\left(23^{\circ} \mathrm{C}\right.$ $\left.\pm 1^{\circ} \mathrm{C}\right)$.

2.2.2. Oxygen Diffusivity. After completion of the fluid absorption experiment, samples were removed from the solutions and stored at a temperature and humidity controlled chamber at $50 \% \pm 1 \% \mathrm{RH}$ and at $23^{\circ} \mathrm{C} \pm 0.5^{\circ} \mathrm{C}$ until mass equilibrium was reached $(\Delta m<0.05 \%)$. After mass equilibrium was reached, the degree of saturation of samples was calculated using the average porosity of the mortar sample (19.6\%) and the mass change from dry state. The degree of saturation for oxygen diffusivity samples was brought to $50 \% \pm 1 \%$ by either drying or wetting the surface of the sample that had not been exposed to $\mathrm{CaCl}_{2}$ solution. All samples were then sealed in plastic bags for a minimum of one week to allow moisture to redistribute before oxygen diffusivity testing.

The oxygen diffusivity was measured using an instrument that was modeled after that developed by Lawrence [33] as shown in Figure 2(b). The samples used for oxygen diffusivity testing were fitted in a rubber ring that is compressed to provide a condition that insures unidirectional flow. The test was performed by exposing the surface of the sample that had been exposed to $\mathrm{CaCl}_{2}$ solution to pure oxygen and the opposite face to pure nitrogen at the same pressure. The oxygen and nitrogen gasses counter diffused through the sample and the oxygen concentration in the outlet cell was measured at 0 and 60 minutes after starting the test. The oxygen diffusivity experiment is described in detail in [34].

2.2.3. Oxygen Permeability. After curing and before exposure to salt, cylinders were cored from large cast beams $(152 \mathrm{~mm} \times$ $152 \mathrm{~mm} \times 584 \mathrm{~mm}$ ) using a $68 \mathrm{~mm} \pm 2 \mathrm{~mm}$ diameter bit. These samples were then cut using a wet saw resulting in samples with a height of $25 \mathrm{~mm} \pm 2 \mathrm{~mm}$ for oxygen permeability measurements. The outer circumference of the specimen was sealed with two layers of epoxy resin. After the epoxy hardened, the prepared samples were then placed in an oven at $60^{\circ} \mathrm{C} \pm 0.5^{\circ} \mathrm{C}$ for a week to remove moisture and allow them to reach mass equilibrium.

As shown in Table 1, the oxygen permeability tests were performed on (a) samples exposed to solutions with varying $\mathrm{CaCl}_{2}$ concentration and (b) samples with varying degree of saturation. For samples exposed to solutions with varying $\mathrm{CaCl}_{2}$ concentration, the samples were completely submerged in $\mathrm{CaCl}_{2}$ solution with $0 \%, 5 \%, 10 \%, 15 \%, 20 \%$, $25 \%$, and $29.8 \%$ salt concentration by mass after having been dried for one week. The samples were then removed from the solutions and conditioned in a temperature and humidity controlled chamber at $50 \% \pm 1 \% \mathrm{RH}$ and at $23^{\circ} \mathrm{C} \pm 0.5^{\circ} \mathrm{C}$ for at least three months until reaching mass equilibrium $(\Delta m<$ $0.05 \%)$. Oxygen permeability tests were then performed with these samples. The degree of saturation of each sample was detected before and after oxygen permeability test for samples exposed to solutions with varying $\mathrm{CaCl}_{2}$ concentration.

For samples tested to determine the influence of varying degree of saturation, dry samples were vacuum-saturated to a degree of saturation of $100 \%$. The vacuum saturation process was as follows: (1) samples were held under vacuum at a pressure of $10 \mathrm{~mm} \mathrm{Hg} \pm 5 \mathrm{~mm} \mathrm{Hg}$ for $3 \mathrm{~h}$, (2) while still under vacuum, deaerated deionized (DI) water was added to the container until the sample was completely submerged, (3) samples remained submerged in DI water under vacuum for $1 \mathrm{~h}$, and (4) the samples remained submerged in the solution until they were tested, approximately $3 \mathrm{~d}$. The samples intended for testing at lower degrees of saturation were removed from the solution and were allowed to air-dry while the mass was monitored every 15-30 min until the desired mass (i.e., degree of saturation) was obtained ( $\Delta m<0.05 \%)$. Samples were then double-sealed in bags where they were kept for one week before the oxygen permeability test was performed to encourage uniform distribution of moisture throughout the sample $[20,34]$. To reach degrees of saturation 

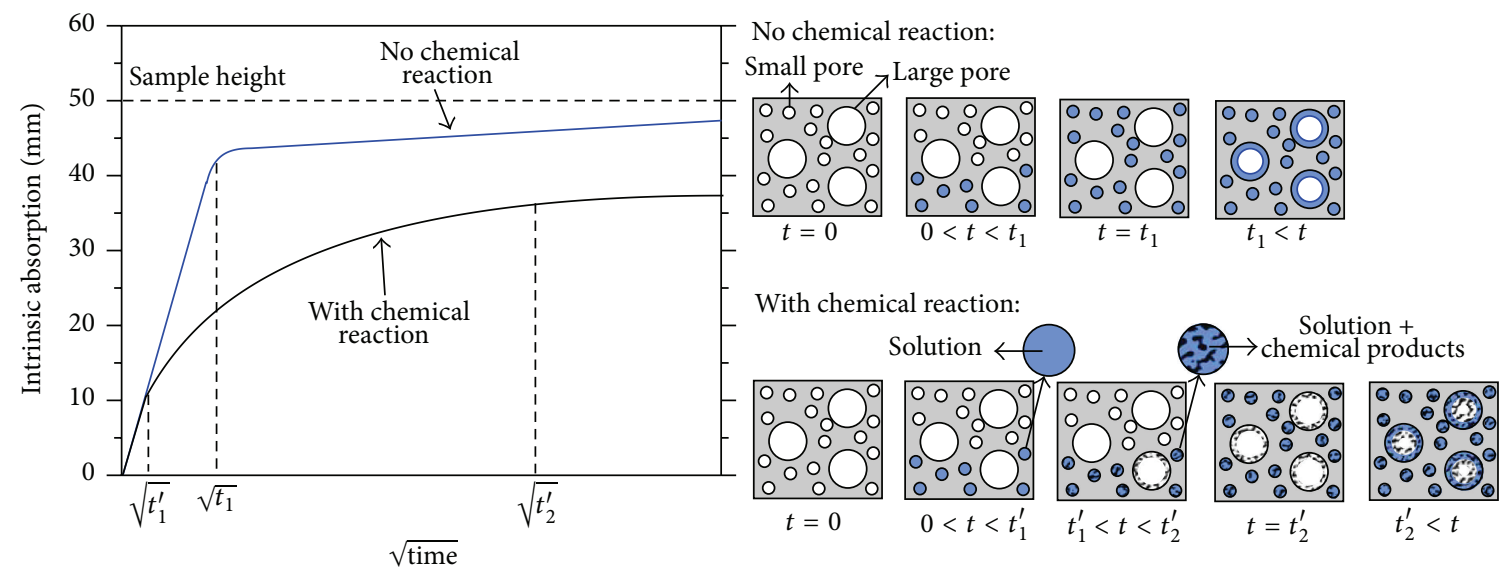

FIGURE 3: Schematic of intrinsic fluid absorption in a cementitious material with and without chemical reaction.

below $60 \%$, samples were dried in a vacuum oven at $50^{\circ} \mathrm{C}$. To obtain degree of saturation equal to $0 \%$, samples were dried in a normal oven at $105^{\circ} \mathrm{C}$ for two days.

Oxygen permeability was measured using a falling head permeameter [35], whose principles are illustrated in Figure 2(c). A unidirectional flow of oxygen through the specimen was created due to the presence of a pressure gradient between the upper and the lower sides of the sample. The bottom surface of the sample was in contact with the pressurized oxygen (initially set to be $100 \mathrm{kPa}$ as a gauge pressure) while the top surface was at atmospheric pressure $(\sim 101.4 \mathrm{kPa})$. The samples were placed inside a rubber collar which was compressed to insure unidirectional flow. The pressure of the oxygen in the chamber was monitored for a $24 \mathrm{hr}$ period using a data acquisition system and data logger.

\section{Results and Discussion}

3.1. Intrinsic Fluid Absorption. ASTM C1585-11 [32] suggests the use of (1) to find the absorption for samples exposed to water:

$$
\text { absorption }\left(\frac{\mathrm{mm}^{3}}{\mathrm{~mm}^{2}}\right)=\frac{m_{t}-m_{o}}{A \cdot \rho_{w}},
$$

where $m_{t}$ is the mass of sample in grams at the time $t$ after exposure to water, $m_{o}$ is the initial mass of sample before exposure, $A$ is the exposed area of the specimen in $\mathrm{mm}^{2}$, and $\rho_{w}$ is the density of water in $\mathrm{g} / \mathrm{mm}^{3}$.

One drawback of this method is that the absorption obtained by ASTM C1585-11 [32] is frequently interpreted as the depth of water penetration in the sample. This however is not correct as it does not account for the sample porosity. In addition, water is used as the fluid that is being absorbed and the equation from ASTM C1585-11 is not directly applicable to other fluids (e.g., salt solution). Increasing the salt concentration in a salt solution can increase viscosity, density, and surface tension in the solution [13-15].

It has been suggested that the absorption and sorptivity are proportional to the square root of the ratio of surface tension and viscosity of the fluid in porous materials $[13,16-$ 18]. An increase in viscosity/density or a decrease in surface tension can decrease solution ingress into a porous material $[13,16-18]$. Equation (2) was developed to obtain an intrinsic absorption (i.e., depth of fluid penetration into the sample) of mortar sample exposed to $\mathrm{CaCl}_{2}$ solutions. The intrinsic absorption is independent of the properties of the solution (i.e., surface tension, viscosity, and density) and it represents the depth of fluid penetration into the sample:

intrinsic absorption $(\mathrm{mm})$

$$
=\frac{m_{t}-m_{o}}{A \cdot \Phi \cdot \rho_{s}\left(1-D_{o}\right)} * \sqrt{\frac{\gamma_{w} \cdot \eta_{s}}{\gamma_{s} \cdot \eta_{w}}}
$$

where $\gamma_{w}$ and $\gamma_{s}$ are the surface tensions for water and solution in $\mathrm{N} / \mathrm{mm}$, respectively; $\eta_{w}$ and $\eta_{s}$ are the viscosities for water and solution in Pa.s, respectively; $\Phi$ is the porosity of the sample in volume fraction; $D_{o}$ is the initial degree of saturation for sample in volume fraction; and $\rho_{s}$ is the density of solution in $\mathrm{g} / \mathrm{mm}^{3}$.

Fluid absorption into a cementitious composite can be idealized as being divided into two regions (assuming no chemical reaction is occurring): (1) initial absorption (time between 0 and $t_{1}$ in Figure 3 ) and (2) secondary absorption (time after $t_{1}$ in Figure 3 ) $[16,18,32,36,37]$. The initial absorption is mainly related to the penetration of fluid into small pores (i.e., gel and capillary pores) [16, 18, 36-41]. Small pores generate a considerable amount of capillary suction which can help fluid to saturate small pores within a very short time. Once the small pores are saturated throughout the whole height of sample (time $t_{1}$ in Figure 3 ), the large pores (i.e., entrapped or entrained pores) in the sample begin to be gradually saturated $[16,18,36-41]$. The portion of absorption which is related to saturating the large pores (after time $t_{1}$ in Figure 3 ) is slow and is called secondary absorption.

Any reaction between a fluid and a hydrated cementitious composite can alter the intrinsic absorption which will be discussed in Section 3.2. 


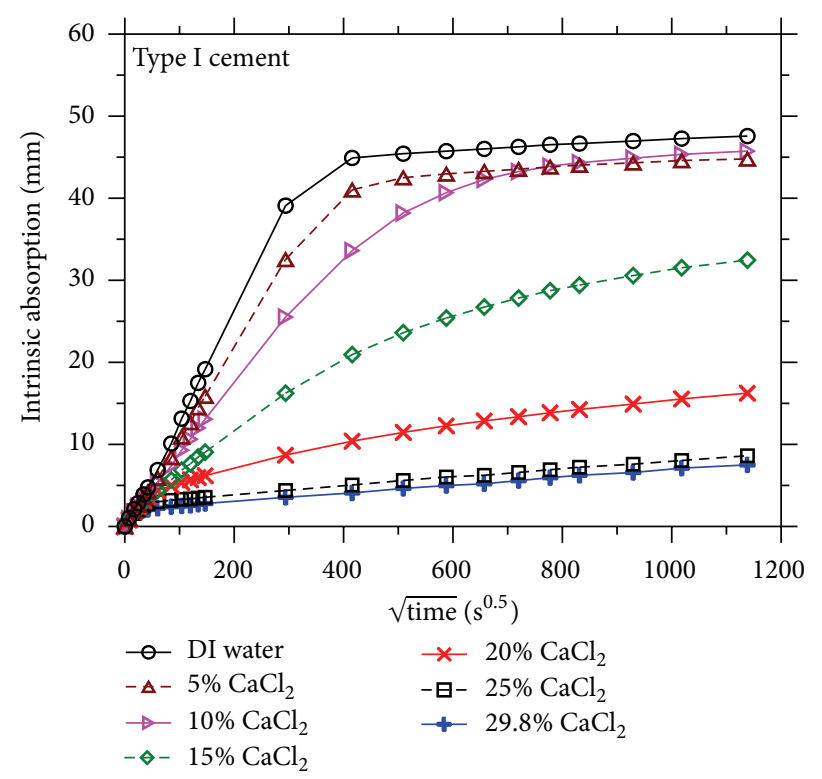

(a)

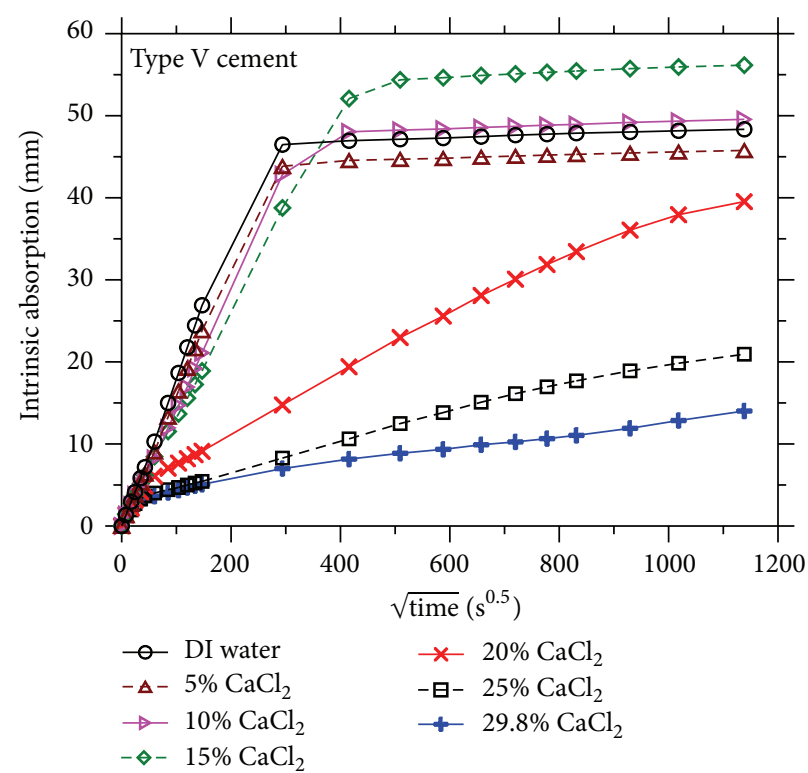

(b)

FIgURE 4: The effect of $\mathrm{CaCl}_{2}$ concentration (\% by mass) on intrinsic absorption for mortar samples prepared using (a) Type I ordinary Portland cement and (b) Type V ordinary Portland cement.

3.2. The Effect of $\mathrm{CaCl}_{2}$ on Intrinsic Fluid Absorption. It has been reported that $\mathrm{CaCl}_{2}$ solution can react with hydrated cementitious binder and produce calcium chloroaluminate phases (such as Friedel's salt and Kuzel's salt) and calcium oxychloride phase $[22,24,26-29,42-45]$. The calcium aluminate phases (e.g., $\mathrm{C}_{3} \mathrm{~A}$, monosulfate, and ettringite) from the hydrated cementitious binder gradually react with $\mathrm{CaCl}_{2}$ resulting in the production of Friedel's salt and Kuzel's salt. The amount of Friedel's salt and Kuzel's salt increases with exposure time, and an increase in salt concentration accelerates the formation of Friedel's salt and Kuzel's salt [24, $27,42-45]$. Calcium oxychloride is produced by the reaction between calcium hydroxide $(\mathrm{CH})$ from the hydrated cementitious binder and $\mathrm{CaCl}_{2}$ solution $[22,26,28,29,45]$. Calcium oxychloride does not form at room temperature (i.e., $\sim 23^{\circ} \mathrm{C}$ ) until $\mathrm{CaCl}_{2}$ salt concentration reaches approximately $12 \%$ by mass in the solution (Figure 1). Beyond this concentration (concentrations greater than $\sim 12 \%$ ), the formation of calcium oxychloride is relatively rapid and its quantity increases as the salt concentration increases [22, 26, 28, 29, 45]. For samples prepared using Type V cement, no Friedel's salt or Kuzel's salt formation is expected (since Type $\mathrm{V}$ cement has relatively no $\mathrm{C}_{3} \mathrm{~A}$, see Table 2), while calcium oxychloride forms for samples prepared using both Type I and Type $\mathrm{V}$ cements as long as $\mathrm{CaCl}_{2}$ concentration is greater than $\sim 12 \%$ by mass in the solution.

The intrinsic absorption obtained for samples as a function of the square root of time is shown in Figure 4. The addition of chemical reaction to the absorption appears to alter the shape of intrinsic absorption curve which is schematically illustrated in Figure 3. First, solution is absorbed into the small pores due to capillary suction during a very short time (time between 0 and $t_{1}^{\prime}$ in Figure 3 ). Beyond time $t_{1}^{\prime}$ in Figure 3, reaction begins and as a result chemical products precipitate in the pores blocking/filling the pore structure. Blocking/filling the pores continues over time and it gradually decreases the rate of intrinsic absorption (between $t_{1}^{\prime}$ and $t_{2}^{\prime}$ in Figure 3). At time $t_{2}^{\prime}$ in Figure 3, all the small pores are filled by either solution or chemical products and, after this time, big pores begin to be occupied. It is expected to have more reduction in fluid absorption as the amount of chemical products (Friedel's salt, Kuzel's salt, and calcium oxychloride) in the pores increases.

Figure 4(a) illustrates the measured intrinsic absorption as a function of square root of time for samples prepared using Type I cement (with $\mathrm{C}_{3} \mathrm{~A}$ ). An increase in $\mathrm{CaCl}_{2}$ concentration results in a decrease in the intrinsic absorption for all of the samples prepared using Type I cement. As the salt concentration increases, the intrinsic absorption reduces primarily due to the fact that an increase in salt concentration increases the formation rate of Friedel's salt and Kuzel's salt [24, 27, 42-45]. A more significant reduction in intrinsic absorption can be seen at the salt concentration of $\sim 12 \%$ or greater. At these concentrations, calcium oxychloride forms (in addition to Friedel's salt and Kuzel's salt) and further blocks/fills the pores.

Figure 4(b) illustrates the intrinsic absorption as a function of square root of time for samples prepared using Type $\mathrm{V}$ cement (with relatively no $\mathrm{C}_{3} \mathrm{~A}$ ). Samples exposed to $\mathrm{CaCl}_{2}$ concentrations less than or equal to $\sim 12 \%$ by mass show a similar trend for intrinsic absorption since no reaction (Friedel's salt and Kuzel's salt formation) is expected to occur for these concentrations. For $\mathrm{CaCl}_{2}$ concentration beyond $\sim 12 \%$, a reduction in intrinsic absorption can be observed as the salt concentration increases, which is mainly due to calcium oxychloride formation in the pores. 


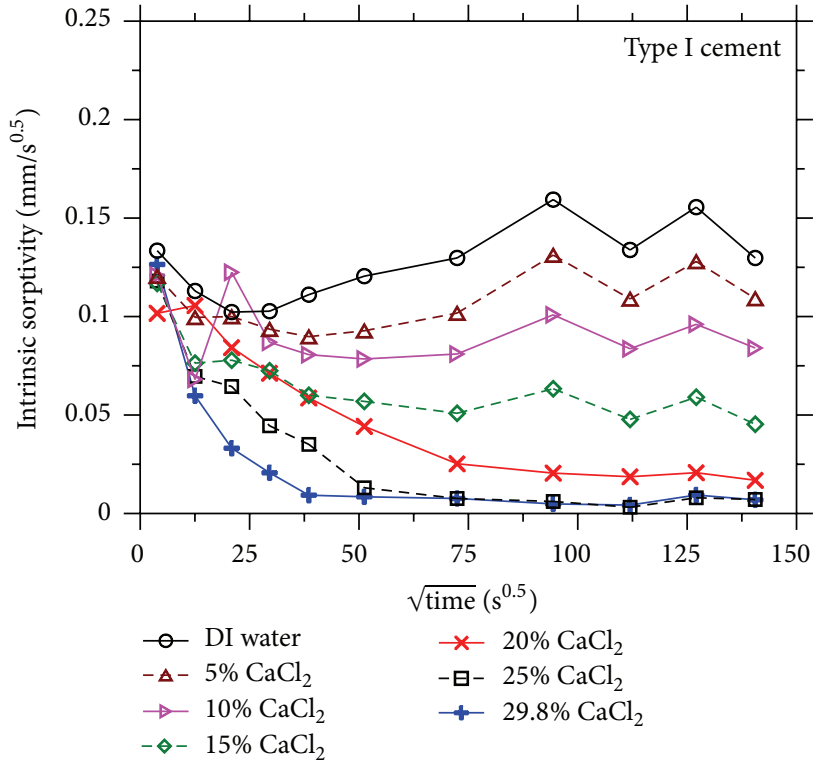

(a)

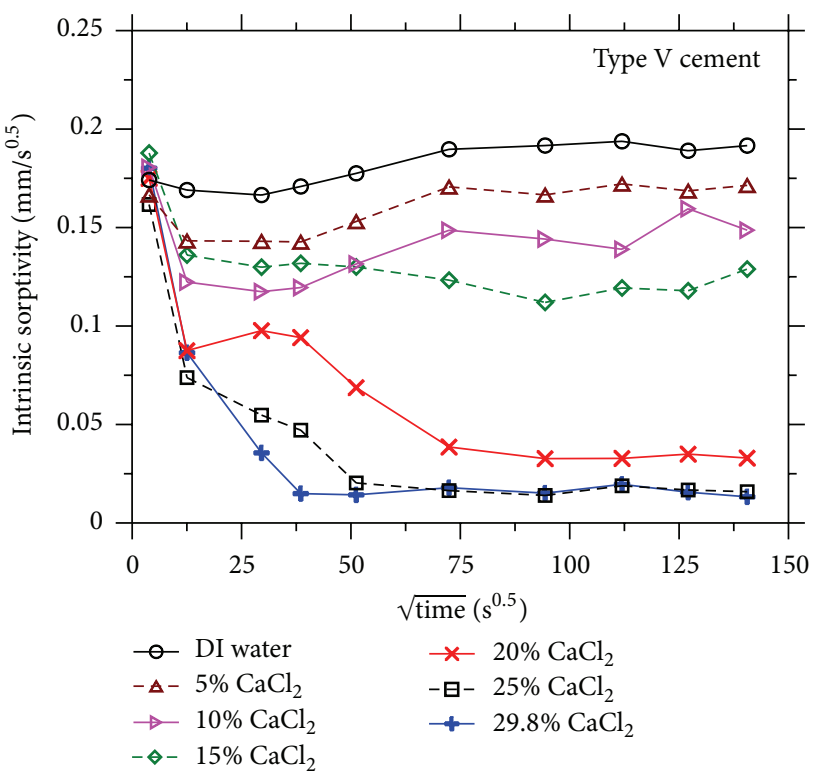

(b)

FIGURE 5: The effect of solution concentration on initial sorptivity of mortar samples prepared using (a) Type I ordinary Portland cement and (b) Type V ordinary Portland cement.

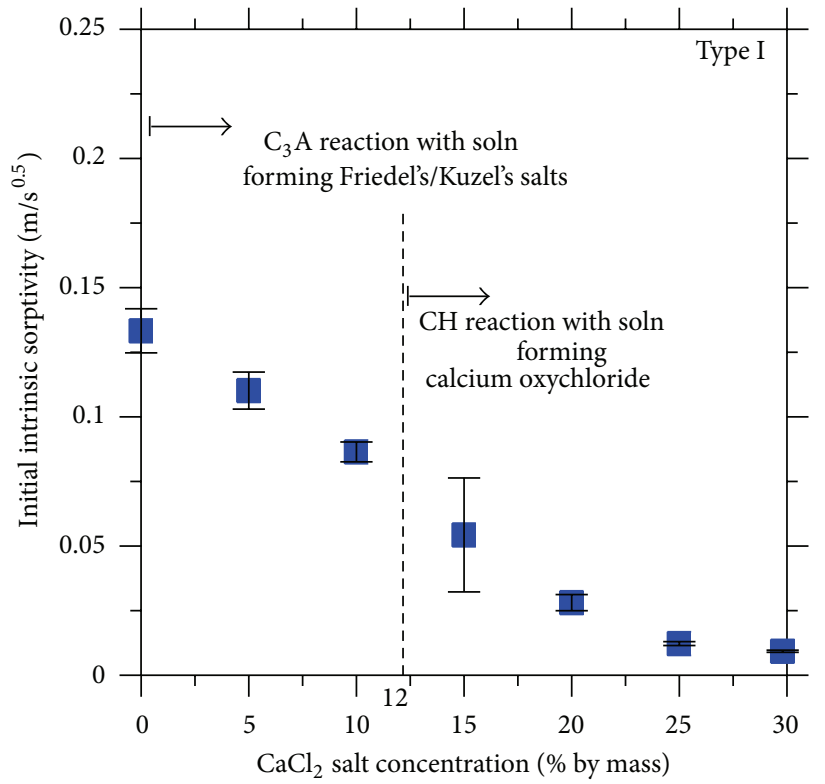

(a)

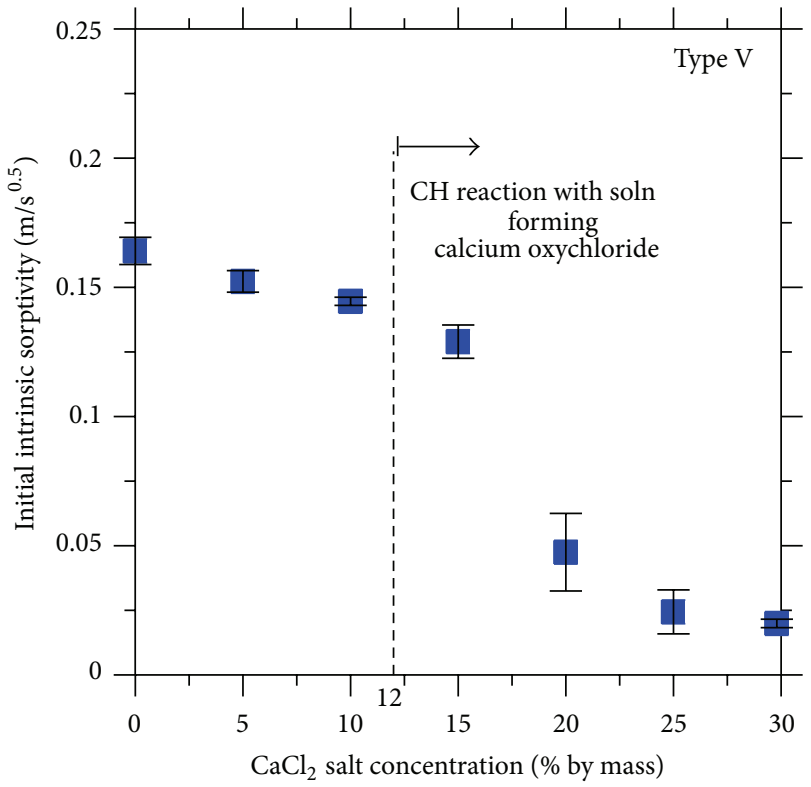

(b)

FIGURE 6: The initial intrinsic sorptivity as a function of $\mathrm{CaCl}_{2}$ concentrations for mortar samples prepared using (a) Type I cement containing $\mathrm{C}_{3} \mathrm{~A}$ and (b) Type $\mathrm{V}$ cement containing approximately no $\mathrm{C}_{3} \mathrm{~A}$.

3.3. The Effect of $\mathrm{CaCl}_{2}$ on Intrinsic Sorptivity. Intrinsic sorptivity is defined as the slope of the intrinsic absorption versus the square root of time curve. The derivative of intrinsic absorption (or intrinsic sorptivity) versus square root of time curve was obtained and is shown in Figure 5 for the first $6 \mathrm{~h}$. A linear trend line was also fitted for the intrinsic absorption versus square root of time curve during first $6 \mathrm{~h}$ and the slope of the linear trend line is reported in
Figure 6 as an initial intrinsic sorptivity. For samples exposed to solutions with high concentrations $(>15 \%)$, the obtained initial intrinsic sorptivity is not a proper indication of initial sorptivity since a nonliner trend can be seen in Figures 4 and 5 due to the presence of chemical reactions between cementitious matrix and $\mathrm{CaCl}_{2}$ solution.

As indicated in Figure 5, the intrinsic sorptivity has a relatively similar value at the beginning of absorption test $(0$ 


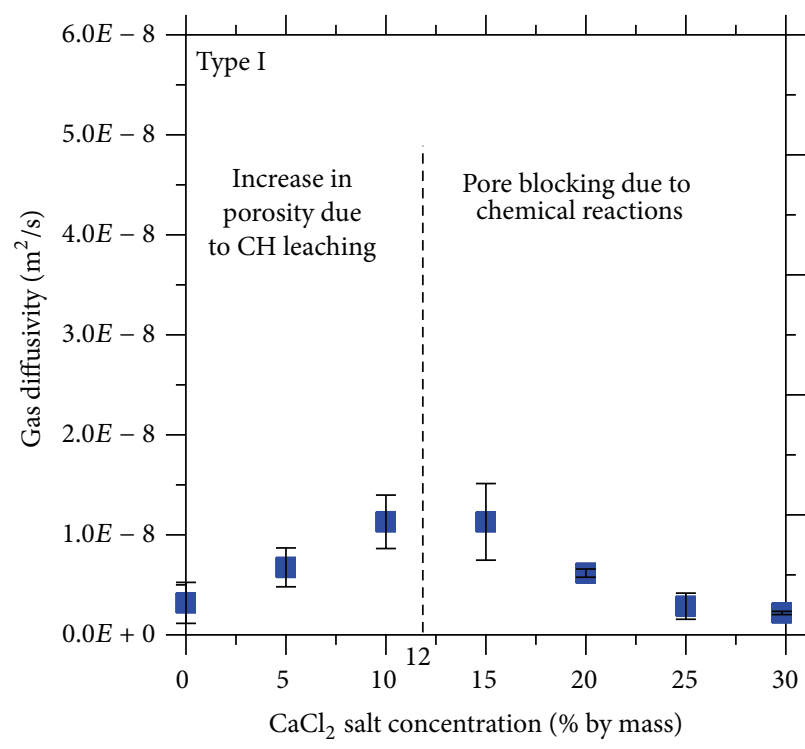

(a)

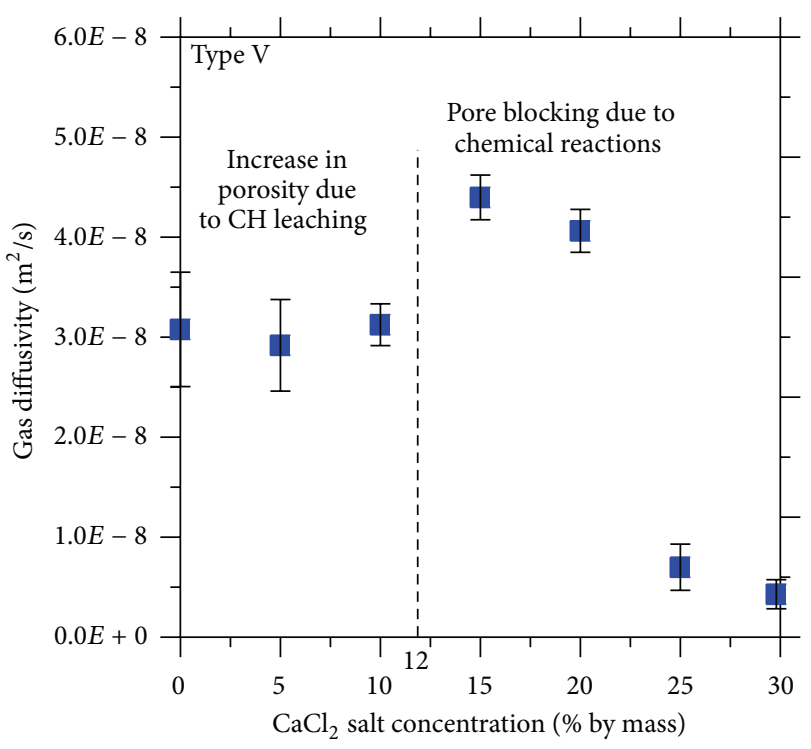

(b)

FIgure 7: The effect of salt concentration on oxygen diffusivity (degree of saturation $=50 \%$ ) for mortar samples prepared using (a) Type I ordinary Portland cement and (b) Type V ordinary Portland cement.

to $1 \mathrm{~min}$ ) for mortar samples saturated with different $\mathrm{CaCl}_{2}$ concentrations, which shows the rate of fluid ingress due to capillary suction. As the $\mathrm{CaCl}_{2}$ concentration increases, a reduction in intrinsic sorptivity over time can be observed in Figure 5. The reduction appears to be primary due to the formation of reaction products (Friedel's/Kuzel's salts and/or calcium oxychloride) in pores which can fill/block the pores (illustrated in Figure 3). The volume of the reaction products would be expected to increase as the exposure time increases. This can further fill/block the pores over time and cause continued reduction in the fluid absorption of the samples.

The initial intrinsic sorptivity as a function of salt concentration is shown in Figure 6. A reduction in initial intrinsic sorptivity can be seen as the $\mathrm{CaCl}_{2}$ concentration increases which may be again due to the chemical reaction products (Friedel's/Kuzel's salts and/or calcium oxychloride). The reduction in initial intrinsic sorptivity is relatively small for salt concentrations less than $\sim 12 \%$. A considerable reduction in initial intrinsic sorptivity can be observed in Figure 6 as the salt concentration becomes greater than $\sim 12 \%$. In general, samples prepared with Type I cement showed a greater reduction in initial intrinsic sorptivity in comparison to samples prepared with Type V cement. The difference in absorption behavior of samples prepared using different cements (i.e., Type I and Type V) may be twofold: (1) for lower $\mathrm{CaCl}_{2}$ concentrations $\left(\sim<12 \% \mathrm{CaCl}_{2}\right)$, Friedel's salts and Kuzel's salts are the only chemical products for samples prepared using Type I cement while no reaction is expected for samples prepared using Type V cement; (2) for higher $\mathrm{CaCl}_{2}$ concentrations $\left(\sim>12 \% \mathrm{CaCl}_{2}\right)$, both Friedel's/Kuzel's salts and calcium oxychloride are produced in the case of using Type I cement.
3.4. The Effect of $\mathrm{CaCl}_{2}$ on Oxygen Diffusivity. Oxygen diffusivity tests were performed on samples after being exposed to the solutions with different $\mathrm{CaCl}_{2}$ concentrations. Since the degree of saturation in mortar sample may have a substantial influence on oxygen diffusivity results, the degree of saturation was kept at 50\% for all samples (described in Section 2.2.2) prior to performing the oxygen diffusivity experiments. The oxygen diffusivity results for mortar samples as a function of $\mathrm{CaCl}_{2}$ concentration in the exposed solution is shown in Figure 7. In general, the gas diffusivity for mortar samples prepared using Type $\mathrm{V}$ cement is higher than the one for mortar sample prepared using Type I cement; this may be due to the fact that different cements may create different pore structure that can influence the gas diffusivity result. As expected, for samples (prepared using either Type I or Type $\mathrm{V}$ cement) exposed to higher concentrations of $\mathrm{CaCl}_{2}$ solution (more than $\sim 12 \%$ ), a reduction in oxygen diffusivity can be seen due to the formation of calcium oxychloride which blocks the pores making the oxygen diffusion more difficult.

An interesting observation is that, for lower concentrations (less than $\sim 12 \%$ ), the oxygen diffusivity increases as the salt concentration increases. This observation appears to be opposite to what one may expect as Friedel's salt and Kuzel's salt can fill/block the pores and reduce the oxygen diffusivity. This may be explained by competing mechanism of calcium hydroxide $(\mathrm{CH})$ dissolution and leaching. Figure 8 shows the solubility of lime $(\mathrm{CaO})$ in $\mathrm{CaCl}_{2}$ solution as the $\mathrm{CaCl}_{2}$ concentration increases [46]. The solubility of lime increases as $\mathrm{CaCl}_{2}$ concentration increases until calcium oxychloride forms and precipitates in the solution. Therefore, mortar samples exposed to $\mathrm{CaCl}_{2}$ solution are susceptible to calcium 


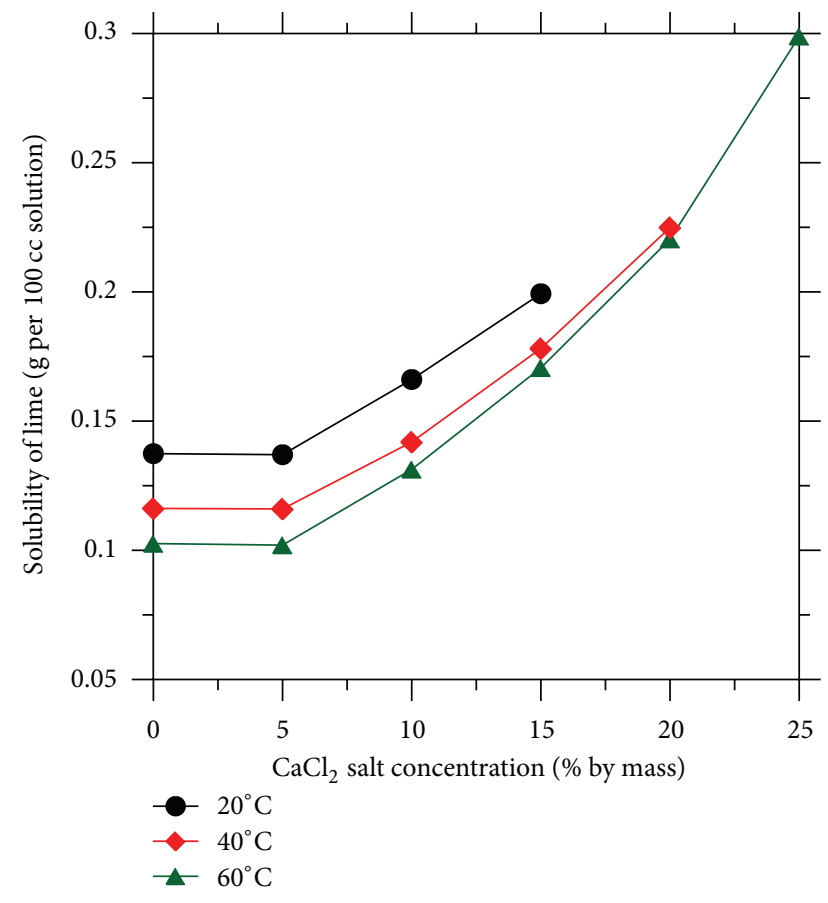

Figure 8: Solubility of lime $(\mathrm{CaO})$ in $\mathrm{CaCl}_{2}$ solution at different temperatures (for samples tested at $20^{\circ} \mathrm{C}$ and $40^{\circ} \mathrm{C}$, precipitation of calcium oxychloride were reported for concentrations more than $15 \%$ and $20 \%$, resp.) [46].

hydroxide (so-called Portlandite in cement chemistry or $\mathrm{CH}$ ) leaching from cementitious binder. An increase in $\mathrm{CaCl}_{2}$ concentration can result in an increase in leaching until the $\mathrm{CaCl}_{2}$ concentration reaches the point when calcium oxychloride forms. Calcium hydroxide leaching at lower $\mathrm{CaCl}_{2}$ concentration (less than $\sim 12 \%$ ) can increase the porosity in mortar sample and increase the oxygen diffusivity. This was not seen in the fluid absorption experiment (Section 3.1) where a decrease in fluid ingress was generally observed as the salt concentration increased. In fact, calcium hydroxide leaching outward of the sample may further reduce fluid ingress toward the sample for samples exposed to a lower concentration of $\mathrm{CaCl}_{2}$ (less than $\sim 12 \%$ ) since calcium hydroxide leaching occurs in the opposite direction of fluid ingress. As a result, calcium hydroxide leaching may be another factor in reducing fluid ingress into samples in addition to the formation of Friedel's/Kuzel's salts for samples exposed to lower concentration of $\mathrm{CaCl}_{2}$ (less than $\sim 12 \%$ ).

\subsection{The Effect of Degree of Saturation on Oxygen Permeability.}

The oxygen permeability of mortar samples with different degrees of saturation was also tested. These tests were performed to determine the effect of the degree of saturation on the oxygen permeability. Figure 9 shows the oxygen permeability results as a function of degree of saturation for all mortar samples. A change in the degree of saturation has a substantial influence on oxygen permeability in the degrees of saturation less than $\sim 70 \%$. The degree of saturation less than $70 \%$ approximately corresponds to removing water from small pores (i.e., gel pores with pore diameter less than $5 \mathrm{~nm}$ ) [38-41]. At degrees of saturation that were greater than $70 \%$, approximately all the small pores become saturated causing disconnection of open/empty pores [38-41]. As a result, oxygen can barely penetrate through the sample at degrees of saturation more than $70 \%$.

A Modified Gaussian Function, as shown in (3), is fitted empirically for the data points (oxygen permeability versus degree of saturation) obtained for samples saturated with DI water:

$$
K_{P}=a+b \cdot \exp \left[-0.5 \cdot\left(\frac{D_{s}-c}{d}\right)^{e}\right]
$$

where $K_{P}$ is the oxygen permeability in $\mathrm{m} / \mathrm{s}$ and $D_{s}$ is the degree of saturation. $a, b, c, d$, and $e$ are coefficients for Modified Gaussian Function. $a, b, c, d$, and $e$ are obtained to be $1 \times 10^{-15}, 4.55 \times 10^{-14}, 0,23$, and 2.2 , respectively, for mortar samples prepared using Type I cement and $5 \times 10^{-15}$, $2.40 \times 10^{-13}, 0,10$, and 1.0 , respectively, for mortar samples prepared using Type $\mathrm{V}$ cement.

3.6. The Effect of $\mathrm{CaCl}_{2}$ on Oxygen Permeability. Oxygen permeability was performed on samples that were exposed to solutions with varying $\mathrm{CaCl}_{2}$ concentrations. Exposure to the $\mathrm{CaCl}_{2}$ solution can alter the degree of saturation in mortar sample as shown in Figure 9. The disparity in the degree of saturation in each sample can substantially alter the transport response of the mortar sample as discussed in Section 3.5 and it is essential to minimize its effect to understand the effect of $\mathrm{CaCl}_{2}$ on the oxygen permeability result. Therefore, the oxygen permeability of mortar samples exposed to $\mathrm{CaCl}_{2}$ solution was modified for degree of saturation equal to $50 \%$ using (3).

The modified oxygen permeabilty is calculated for the mortar samples exposed to $\mathrm{CaCl}_{2}$ solution and it is shown in Figure 10 as a function of $\mathrm{CaCl}_{2}$ concentration in the solution. A similar trend as was observed for oxygen diffusivity (Section 3.4) can be observed for oxygen permeability as well: (1) an increase in $\mathrm{CaCl}_{2}$ concentration increases the oxygen permeability until the salt concentration reaches $\sim 12 \%$ due to calcium hydroxide leaching increasing the porosity of the mortar sample, and (2) beyond this point, the formation of calcium oxychloride in pores fills the pores, decreasing the oxygen permeability.

\section{Conclusion and Summary}

This paper describes tests to measure the fluid absorption and gas transport (oxygen diffusivity/permeability) properties of mortars exposed to $\mathrm{CaCl}_{2}$ solutions. The mortars were prepared using two cements (Type I and Type V). The mortars were exposed to solutions with varying $\mathrm{CaCl}_{2}$ concentrations and with varying degrees of saturation. Based on the results of this study, the following conclusions can be drawn:

(i) Calcium oxychloride formation can substantially decrease fluid absorption and gas transport in cementitious materials. A substantial decrease in transport properties (i.e., absorption, oxygen diffusivity, 


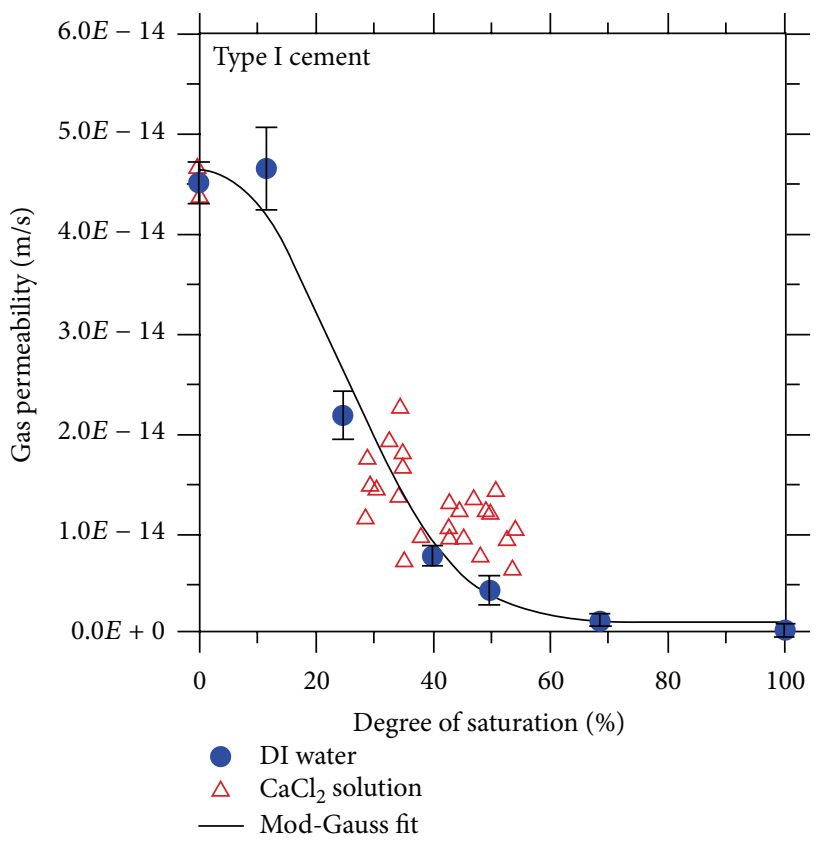

(a)

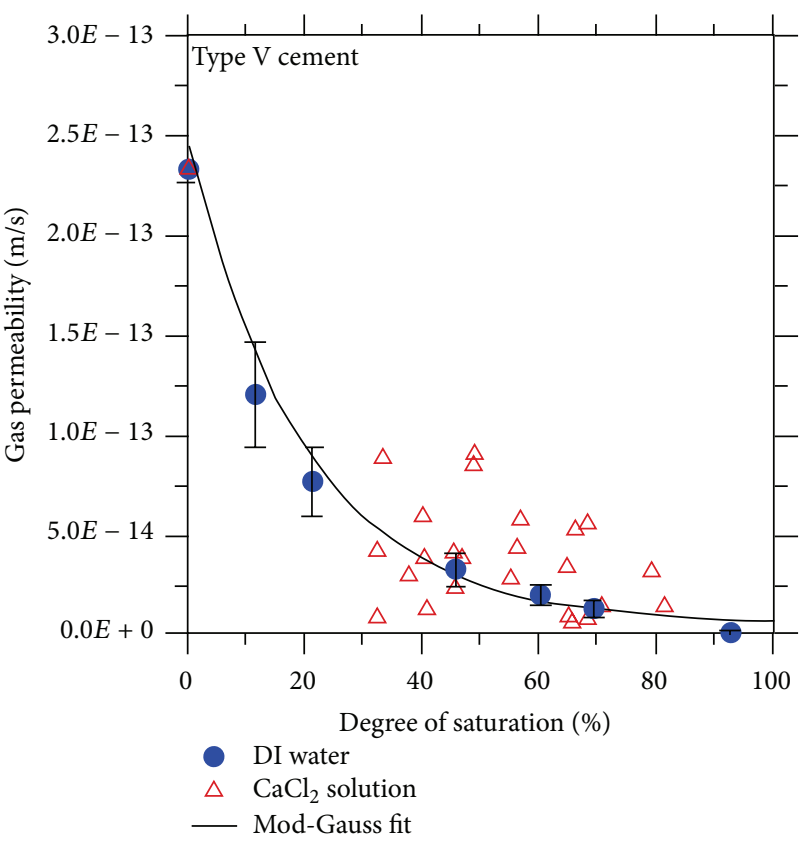

(b)

Figure 9: The effect of degree of saturation on oxygen permeability for mortar samples prepared using (a) Type I ordinary Portland cement and (b) Type V ordinary Portland cement (notice that modified Gaussian function is only fitted for DI water points and the scale for $y$-axis is not identical).

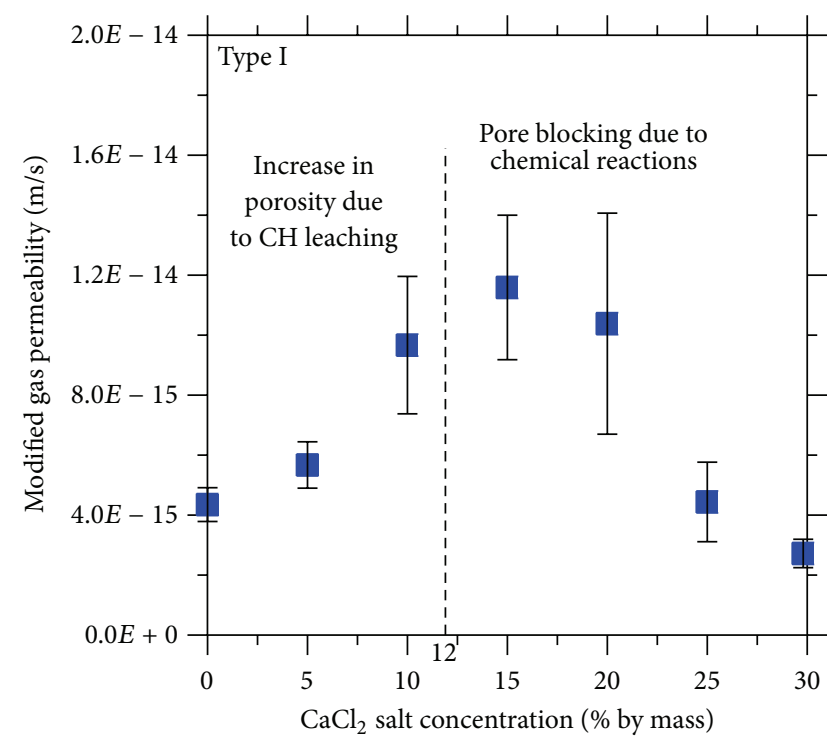

(a)

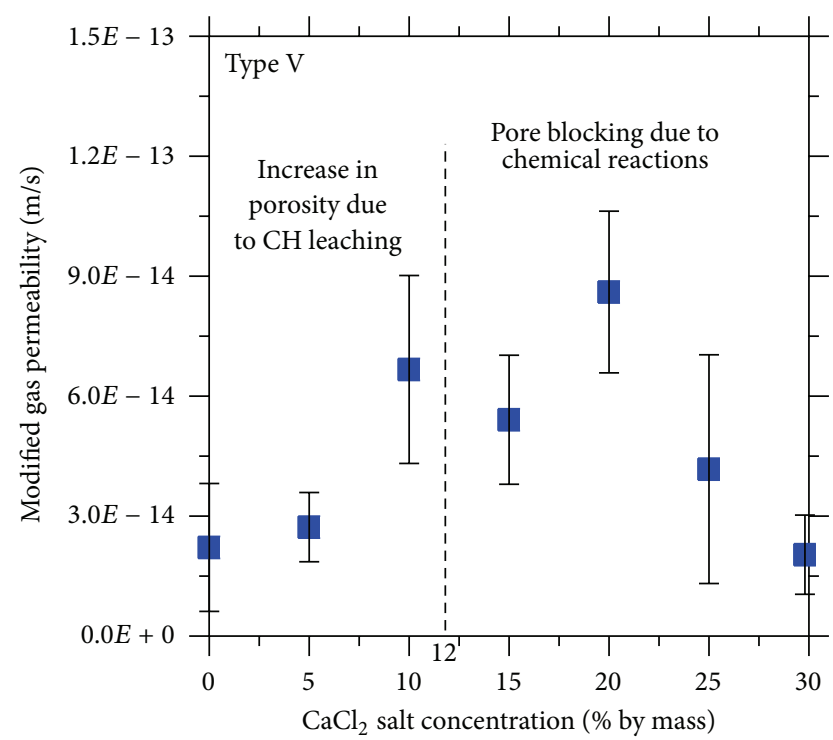

(b)

FIGURE 10: The effect of salt concentration on modified oxygen permeability for $50 \%$ degree of saturation in mortar samples prepared using (a) Type I ordinary Portland cement and (b) Type V ordinary Portland cement (notice that the scale for $y$-axis is not identical).

and oxygen permeability) was observed for samples exposed to solutions of higher $\mathrm{CaCl}_{2}$ concentrations (solution with concentrations more than $\sim 12 \%$ by mass). This is mainly due to the fact that, at concentrations greater than $\sim 12 \%$, calcium oxychloride is stable at room temperature $\left(23^{\circ} \mathrm{C} \pm 1^{\circ} \mathrm{C}\right)$ and can cause blocking or filling the pores.

(ii) Calcium hydroxide leaching influenced the gas transport properties of cementitious material exposed to $\mathrm{CaCl}_{2}$ solutions with low concentrations $(\sim<12 \%)$. As 
the $\mathrm{CaCl}_{2}$ concentration increases, calcium hydroxide leaching also increases and can increase the concrete porosity. Any increase in concrete porosity can further increase gas and fluid ingress in cementitious materials.

(iii) Comparing samples prepared using Type I cement (with 9\% $\mathrm{C}_{3} \mathrm{~A}$ ) and Type $\mathrm{V}$ cement (with approximately no $\mathrm{C}_{3} \mathrm{~A}$ ) shows that the formation of calcium chloroaluminate phases (e.g., Friedel's salt and Kuzel's salts) can also reduce the gas and fluid ingress properties in the mortar. The formation of Friedel's salt and Kuzel's salts (in addition to calcium oxychloride) in mortar samples prepared using Type I cement can further block or fill the concrete pores, thereby decreasing fluid and gas transport in mortar sample.

(iv) Deicing salts can increase the saturation state of cementitious materials resulting in an increase in the equilibrium relative humidity of the pore solution. The change in the saturation state of cementitious materials can substantially alter the transport properties of concrete. For degrees of saturation less than $70 \%$, an increase in degree of saturation caused a considerable reduction in oxygen permeability. For degrees of saturation more than $70 \%$, however, the change in oxygen permeability was relatively negligible since the small pores (i.e., gel pores with pore diameter less than $5 \mathrm{~nm}$ ) become saturated causing disconnection of open/empty big pores. As a result, oxygen cannot easily penetrate through the sample at degrees of saturation more than $70 \%$.

(v) Transport properties are often used in concrete to predict the time in which the chloride reaches its threshold value to initiate the corrosion of reinforcing steel or to estimate the time when the degree of saturation in concrete reaches its critical value to cause freeze-thaw damage. The results of this study show that, at high concentration of $\mathrm{CaCl}_{2}$ (more than $12 \%)$, the formation of chemical reactions may be a dominant factor in determination of service life (or damage development) rather than corrosion of reinforcement or freeze-thaw damage since fluid and gas ingress was not considerable at high concentrations due to pore blocking caused by chemical reactions. At low concentration (less than $12 \%$ ), however, calcium hydroxide leaching due to $\mathrm{CaCl}_{2}$ solution exposure may increase the porosity, thereby decreasing the service life of concrete.

\section{Disclaimer}

The contents of this paper reflect the views of the authors, who are responsible for the facts and the accuracy of the data presented herein, and do not necessarily reflect the official views or policies of the Indiana Department of Transportation, nor do the contents constitute a standard, specification, or regulation.

\section{Conflict of Interests}

The authors declare that there is no conflict of interests regarding the publication of this paper.

\section{Acknowledgments}

This work was supported in part by the Joint Transportation Research Program administered by the Indiana Department of Transportation in the National Pooled Fund Study and the authors gratefully acknowledge that support. The experiments reported in this paper were conducted in the Pankow Materials Laboratories at Purdue University. The authors acknowledge the support that has made this laboratory and its operation possible.

\section{References}

[1] V. G. Papadakis, "Service life prediction of a reinforced concrete bridge exposed to chloride induced deterioration," Advances in Concrete Construction, vol. 1, no. 3, pp. 201-213, 2013.

[2] X. Shi, N. Xie, K. Fortune, and J. Gong, "Durability of steel reinforced concrete in chloride environments: an overview," Construction and Building Materials, vol. 30, pp. 125-138, 2012.

[3] T. C. Powers, L. E. Copeland, J. C. Hayes, and H. M. Mann, "Permeability of Portland cement paste," Journal of the American Concrete Institute, vol. 51, pp. 285-298, 1954.

[4] H. Hilsdorf and J. Kropp, Performance Criteria for Concrete Durability (Rilem Report, No 12), CRC Press, 1995.

[5] F. P. Glasser, J. Marchand, and E. Samson, "Durability of concrete-degradation phenomena involving detrimental chemical reactions," Cement and Concrete Research, vol. 38, no. 2, pp. 226-246, 2008.

[6] P. B. Bamforth, "The relationship between permeability coefficients for concrete obtained using liquid and gas," Magazine of Concrete Research, vol. 39, no. 138, pp. 3-11, 1987.

[7] W. Li, M. Pour-Ghaz, J. Castro, and J. Weiss, "Water absorption and critical degree of saturation relating to freeze-thaw damage in concrete pavement joints," Journal of Materials in Civil Engineering, vol. 24, no. 3, pp. 299-307, 2012.

[8] G. Fagerlund, "On the service life of concrete exposed to frost action," in Freeze-Thaw Durability of Concrete, J. Marchand, M. Pigeon, and M. Setzer, Eds., pp. 23-41, E \& FN Spon, London, UK, 1997.

[9] Y. Farnam, D. Bentz, A. Sakulich, D. Flynn, and J. Weiss, "Measuring freeze and thaw damage in mortars containing deicing salt using a low-temperature longitudinal guarded comparative calorimeter and acoustic emission," Advances in Civil Engineering Materials, vol. 3, no. 1, pp. 316-337, 2014.

[10] Y. Farnam, H. Todak, R. Spragg, and J. Weiss, "Electrical response of mortar with different degrees of saturation and deicing salt solutions during freezing and thawing," Cement and Concrete Composites, vol. 59, pp. 49-59, 2015.

[11] Y. Qian, Y. Farnam, and J. Weiss, "Using acoustic emission to quantify freeze-thaw damage of mortar saturated with $\mathrm{NaCl}$ solutions," in Proceedings of the 4th International Conference on Durability of Concrete Structures (ICDCS '14), pp. 32-37, Purdue University Libraries Scholarly Publishing Services, July 2014. 
[12] W. Jones, Y. Farnam, P. Imbrock et al., An Overview of Joint Deterioration in Concrete Pavement: Mechanisms, Solution Properties, and Sealers, Purdue University, West Lafayette, Ind, USA, 2013.

[13] R. P. Spragg, J. Castro, W. Li, M. Pour-Ghaz, P.-T. Huang, and J. Weiss, "Wetting and drying of concrete using aqueous solutions containing deicing salts," Cement and Concrete Composites, vol. 33, no. 5, pp. 535-542, 2011.

[14] C. Villani, R. Spragg, M. Pour-Ghaz, and W. Jason Weiss, “The influence of pore solutions properties on drying in cementitious materials," Journal of the American Ceramic Society, vol. 97, no. 2, pp. 386-393, 2014.

[15] M. R. Conde, "Properties of aqueous solutions of lithium and calcium chlorides: formulations for use in air conditioning equipment design," International Journal of Thermal Sciences, vol. 43 , no. 4 , pp. 367-382, 2004.

[16] C. Hall, J. Marchand, G. Gerard, and M. Sosoro, "Transport of fluids in homogenous isotropic cementitous composites," in Penetration and Permeability of Concrete, H. W. Reinhardt, Ed., RILEM Report 16, pp. 5-79, 1997.

[17] S. Kelham, "A water absorption test for concrete," Magazine of Concrete Research, vol. 40, no. 143, pp. 106-110, 1988.

[18] C. Hall and W. D. Hoff, Water Transport in Brick, Stone and Concrete, Spon Press, New York, NY, USA, 2nd edition, 2012.

[19] L. Greenspan, "Humidity fixed points of binary saturated aqueous solutions," Journal of Research of the National Bureau of Standards A: Physics and Chemistry, vol. 81, pp. 89-96, 1997.

[20] C. Villani, T. E. Nantung, and W. J. Weiss, "The influence of deicing salt exposure on the gas transport in cementitious materials," Construction and Building Materials, vol. 67, part A, pp. 108-114, 2014.

[21] G. W. Scherer, "Crystallization in pores," Cement and Concrete Research, vol. 29, no. 8, pp. 1347-1358, 1999.

[22] Y. Farnam, S. Dick, A. Wiese, J. Davis, D. Bentz, and J. Weiss, "The influence of calcium chloride deicing salt on phase changes and damage development in cementitious materials," Cement and Concrete Composites. Submitted.

[23] Y. Farnam, A. Wiese, D. Bentz, J. Davis, and J. Weiss, "Damage development in cementitious materials exposed to magnesium chloride deicing salt," Construction and Building Materials. In press.

[24] Y. Bu, D. Luo, and J. Weiss, “Using Fick's second law and nernstplanck approach in prediction of chloride ingress in concrete materials," Advances in Civil Engineering Materials, vol. 3, no. 1, 2014.

[25] Y. Farnam, D. Bentz, A. Hampton, and W. J. Weiss, "Acoustic emission and low-temperature calorimetry study of freeze and thaw behavior in cementitious materials exposed to sodium chloride salt," Transportation Research Record, vol. 2441, pp. 8190, 2014.

[26] K. Peterson, G. Julio-Betancourt, L. Sutter, R. D. Hooton, and D. Johnston, "Observations of chloride ingress and calcium oxychloride formation in laboratory concrete and mortar at $5^{\circ}$ C, Cement and Concrete Research, vol. 45, no. 1, pp. 79-90, 2013.

[27] L. Sutter, K. Peterson, G. Julio-Betancourt, D. Hooton, T. V. Dam, and K. Smith, "The deleterious chemical effects of concentrated deicing solutions on Portland cement concrete," Final Report for the South Dakota Department of Transportation, 2008.
[28] L. Sutter, K. Peterson, S. Touton, T. van Dam, and D. Johnston, "Petrographic evidence of calcium oxychloride formation in mortars exposed to magnesium chloride solution," Cement and Concrete Research, vol. 36, no. 8, pp. 1533-1541, 2006.

[29] C. Villani, Y. Farnam, T. Washington, J. Jain, and J. Weiss, "Performance of conventional portland cement and calcium silicate based carbonated cementitious systems during freezing and thawing in the presence of calcium chloride deicing salts," Journal of the Transportation Research Record. In press.

[30] ASTM, "Standard practice for mechanical mixing of hydraulic cement pastes and mortars of plastic consistency," ASTM C305, ASTM International, West Conshohocken, Pa, USA, 2012.

[31] ASTM, "ASTM C642-standard test method for density, absorption, and voids in hardened concrete," in Annual Book of ASTM Standards, ASTM International, West Conshohocken, $\mathrm{Pa}, \mathrm{USA}, 2013$.

[32] ASTM International, ASTM C1585-Standard Test Method for Measurement of Rate of Absorption of Water by HydraulicCement Concretes, ASTM International, West Conshohocken, Pa, USA, 2011.

[33] C. D. Lawrence, "Transport of oxygen through concrete," in Proceedings of the British Ceramic Society Meeting, Chemistry and Chemically-Related Properties of Cement, D. P. Glasser, Ed., pp. 277-293, British Ceramic Society, London, UK, 1984.

[34] C. Villani, R. Loser, M. J. West, C. Di Bella, P. Lura, and W. J. Weiss, "An inter lab comparison of gas transport testing procedures: oxygen permeability and oxygen diffusivity," Cement and Concrete Composites, vol. 53, pp. 357-366, 2014.

[35] Y. Ballim, "A low cost, falling head permeameter for measuring concrete gas permeability," Concrete Beton, vol. 61, pp. 13-81, 1991.

[36] H. Todak, C. Lucero, and J. Weiss, "Why is the air there? Thinking about freeze-thaw in terms of saturation," Concrete inFocus, pp. 3-7, 2015, http://www.nrmca.org/news/connections/.

[37] C. L. Lucero, D. P. Bentz, D. S. Hussey, D. L. Jacobson, and W. J. Weiss, "Using neutron radiography to quantify water transport and the degree of saturation in entrained air cement based mortar," Physics Procedia. In press.

[38] D. P. Bentz and W. J. Weiss, "Internal curing: a 2010 state-of-theart review," NISTIR 7765, National Institute of Standards and Technology, Gaithersburg, Md, USA, 2010.

[39] T. C. Powers and T. L. Brownyard, "Studies of the physical properties of Hardened Portland cement paste," ACI Journal Proceedings, vol. 43, pp. 933-992, 1946.

[40] J. F. Young, "A review of the pore structure of cement paste and concrete and its influence on permeability," in Permeability of Concrete, vol. 108, pp. 1-18, 1988.

[41] D. A. Whiting and M. A. Nagi, Manual on Control of Air Content in Concrete, Portland Cement Association, 1998.

[42] A. Mesbah, M. François, C. Cau-dit-Coumes et al., "Crystal structure of Kuzel's salt $3 \mathrm{CaO} \cdot \mathrm{Al}_{2} \mathrm{O}_{3} \cdot 1 / 2 \mathrm{CaSO}_{4} \cdot 1 / 2 \mathrm{CaCl}_{2} \cdot 11 \mathrm{H}_{2} \mathrm{O}$ determined by synchrotron powder diffraction," Cement and Concrete Research, vol. 41, no. 5, pp. 504-509, 2011.

[43] P. Brown and J. Bothe, "The system $\mathrm{CaO}-\mathrm{Al}_{2} \mathrm{O}_{3}-\mathrm{CaCl}_{2}-\mathrm{H}_{2} \mathrm{O}$ at $23 \pm 2{ }^{\circ} \mathrm{C}$ and the mechanisms of chloride binding in concrete," Cement and Concrete Research, vol. 34, pp. 1549-1553, 2004.

[44] A. K. Suryavanshi, J. D. Scantlebury, and S. B. Lyon, "Mechanism of Friedel's salt formation in cements rich in tri-calcium aluminate," Cement and Concrete Research, vol. 26, no. 5, pp. 717-727, 1996. 
[45] M. Collepardi, L. Coppola, and C. Pistolesi, "Durability of concrete structures exposed to $\mathrm{CaCl}_{2}$ based deicing salts," in Proceedings of the 3rd CANMET/ACI International Conference on Durability of Concrete, V. M. Malhotra, Ed., ACI SP-145, pp. 107-120, Nice, France, 1994.

[46] United States. Bureau of Soils, Bulletin, Issues 42-53, Nabu Press, 2012. 

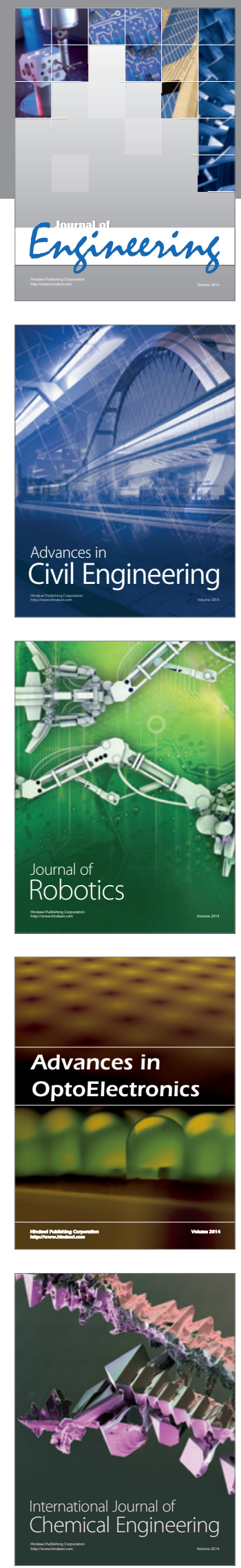

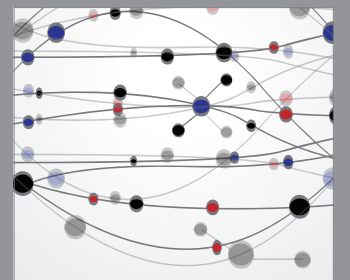

The Scientific World Journal
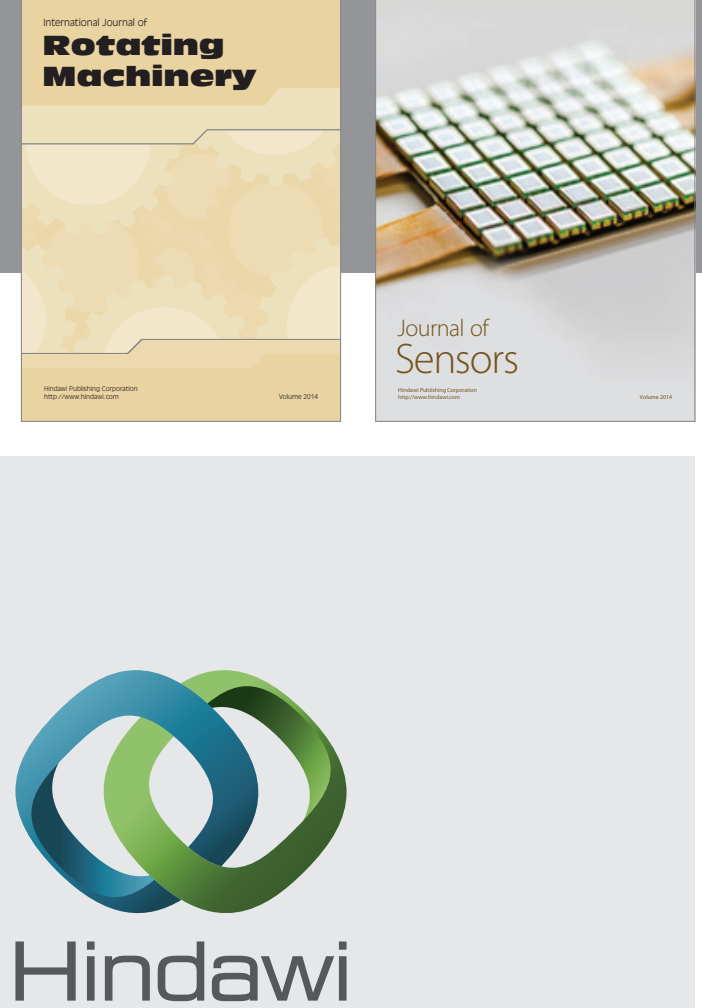

Submit your manuscripts at http://www.hindawi.com
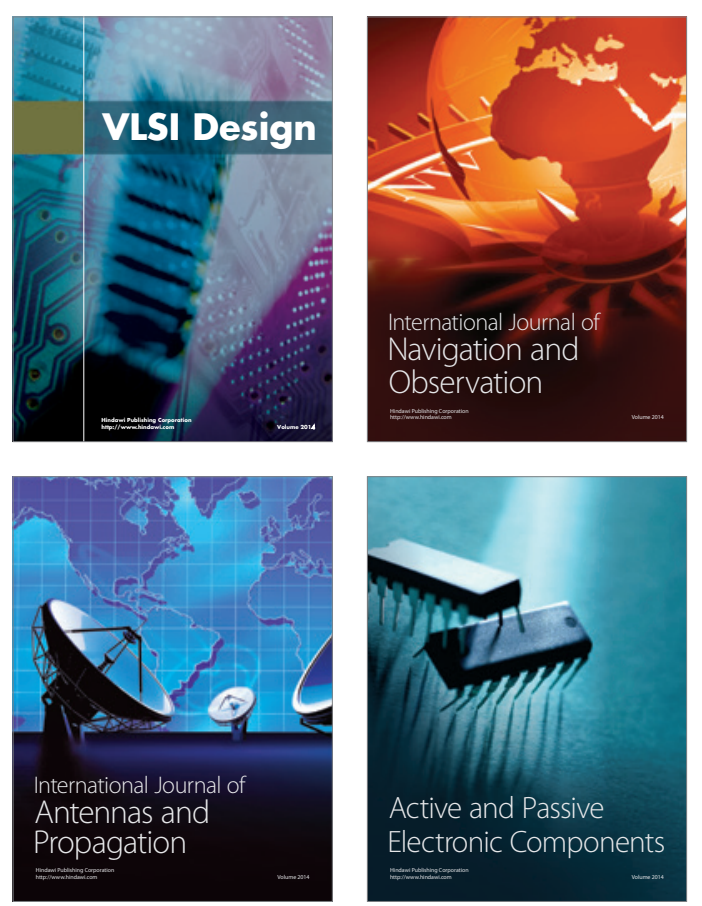
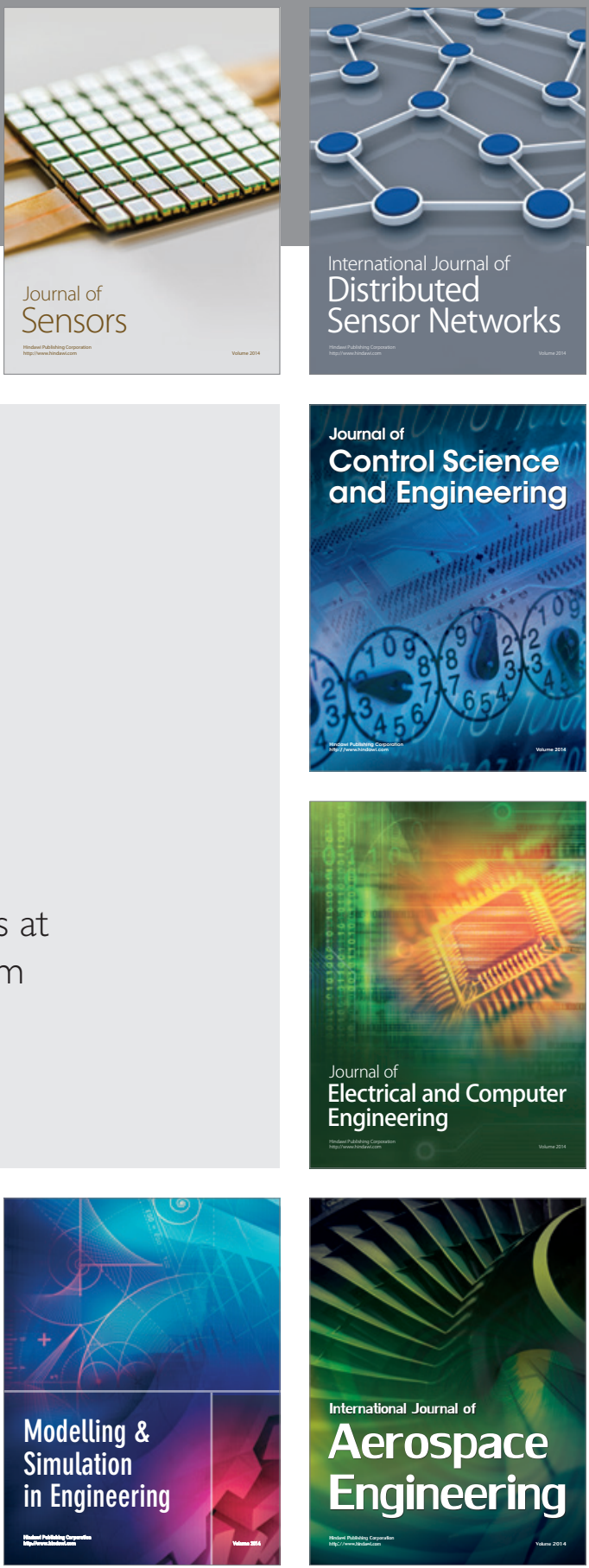

Journal of

Control Science

and Engineering
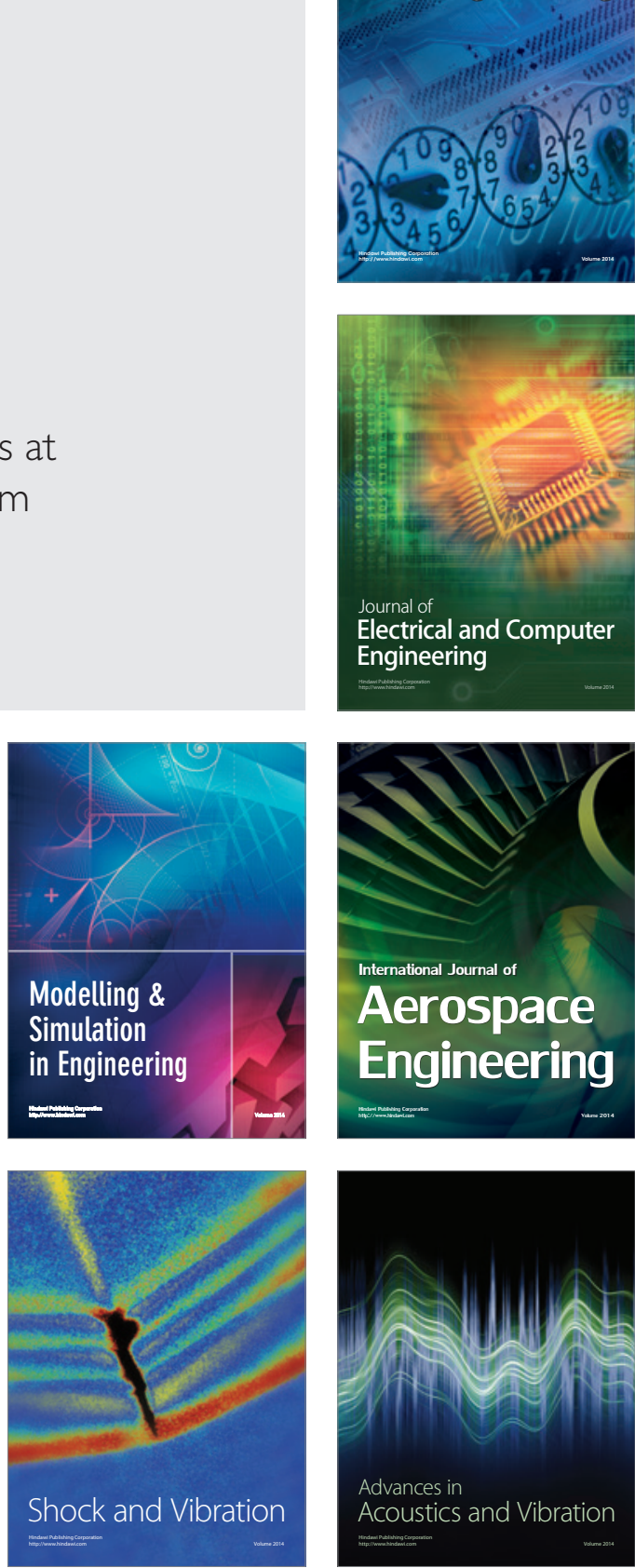